\title{
RAIRO
}

ANALYSE NUMÉRIQUE

Michel CROUZEIX

FRANÇOISE RUAMPS

\section{On rational approximations to the exponential}

RAIRO - Analyse numérique, tome 11, no 3 (1977), p. 241-243.

<http://www.numdam.org/item?id=M2AN_1977_11_3_241_0>

(C) AFCET, 1977, tous droits réservés.

L'accès aux archives de la revue «RAIRO - Analyse numérique » implique l'accord avec les conditions générales d'utilisation (http://www.numdam.org/ legal.php). Toute utilisation commerciale ou impression systématique est constitutive d'une infraction pénale. Toute copie ou impression de ce fichier doit contenir la présente mention de copyright.

\section{Numdam}

Article numérisé dans le cadre du programme

Numérisation de documents anciens mathématiques

http://www.numdam.org/ 


\title{
ON RATIONAL APPROXIMATIONS TO THE EXPONENTIAL (1)
}

\author{
by Michel Crouzeix and Françoise Ruamps $\left({ }^{2}\right)$
}

Communiqué par P.-A. Raviart

Abstract. - We give in this paper a simple characterization of the A-acceptability property for a family of rational approximations to $e^{-z}$. This result, which is implicitely contained in Norsett [3] is obtained here in a direct way. As a corollary, we obtain the results of Ehle [1] on Pade approximations to $e^{-z}$.

Let $r(z)=\frac{1+a_{1} z+\ldots+a_{n} z^{n}}{1+b_{1} z+\ldots+b_{n} z^{n}}, a_{i}, b_{i} \in \mathbf{R}$, be a rational approximation to $e^{-z}$. The function $r(z)$ is said to be $A$-acceptable iff

$$
|r(z)| \leqslant 1 \text { for } z \in \mathbf{C} \operatorname{Re} z \geqslant 0 .
$$

This paper is devoted to the proof of the following.

THEOREM : Assume that the rational function $r(z)$ satisfies

$$
r(z)=e^{-z}+0\left(z^{2 n-1}\right) \quad(z \rightarrow 0)
$$

Then $r(z)$ is A-acceptable iff

$$
\left|a_{n}\right| \leqslant b_{n}
$$

or

$$
r(z) \text { is reducible. }
$$

Proof: We set $p(z)=1+a_{1} z+\ldots+a_{n} z^{n}$

$$
q(z)=1+b_{1} z+\ldots+b_{n} z^{n}
$$

(1) Manuscrit reçu le 4 janvier 1977.

(2) U.E.R. Mathématiques et Informatique Université de Rennes.

R.A.I.R.O. Analyse Numérique/Numerical Analysis, vol. 11, n 3, 1977 


\section{THE CONDITION IS NECESSARY}

Assume that $r(z)$ is $A$-acceptable. Then the poles of $r(z)$ belong to the open half-plane $\operatorname{Re} z<0$ and we have $\lim _{|z| \rightarrow \infty}|r(z)| \leqslant 1$. Moreover, if $r=p / q$ is irreducible, we have $b_{n} \geqslant 0$ (otherwise the polynomial $q$ would have a positive root) and $\left|a_{n}\right| \leqslant b_{n}$.

\section{THE CONDITION IS SUFFICIENT}

Let us prove it by induction. We first notice that the result is clearly true for $n=1$. Let us assume that the property is true for $n-1$. We consider two cases:

$1^{\text {st }}$ case $r$ is reducible or $a_{n}=b_{n}=0$. Then it follows from (2) that $r$ is the $(n-1 / n-1)$ - th Padé approximation to $e^{-z}$ and, from Hummel and Seebeck [2] and Padé [4] $r(z)$ may be written on the form $\frac{A_{n-1}(-z)}{A_{n-1}(z)}$ with

$$
A_{n-1}(z)=\sum_{k=0}^{n-1} \frac{(2 n-2-k) !(n-1) !}{(2 n-2) ! k !(n-1-k) !} z^{k}
$$

Therefore $r$ satisfies the theorem hypothesis for $n-1$ and it follows from the induction hypothesis that $r$ is $A$-acceptable.

$2^{\text {nd }}$ case $b_{n} \neq 0$ and $\left|a_{n}\right| \leqslant b_{n}$. We set $(a, b)=\left(a_{1}, \ldots, a_{n}, b_{1}, \ldots, b_{n}\right)$ and $E_{n}=\left\{(a, b) ; r(z)=e^{-z}+0\left(z^{2 n-1}\right),\left|a_{n}\right| \leqslant b_{n}\right.$ and $\left.b_{n} \neq 0\right\}$.

The subset $E_{n}$ of $\mathbf{R}^{2 n}$ is convex and therefore connected.

For all $(a, b) \in E_{i n}$ we have

$$
|r(i y)|^{2}=\frac{1+\alpha_{1} y^{2}+\alpha_{2} y^{4}+\ldots+\alpha_{n} y^{2 n}}{1+\beta_{1} y^{2}+\beta_{2} y^{4}+\ldots+\beta_{n} y^{2 n}}=1+0\left(y^{2 n-1}\right)
$$

and then we have $\alpha_{1}=\beta_{1}, \ldots, \alpha_{n-1}=\beta_{n-1}$. From the inequality $\left|a_{n}\right| \leqslant b_{n}$ it follows that $\alpha_{n} \leqslant \beta_{n}$ and therefore we have for all $(a, b) \in E_{n}$ :

$$
|r(i y)| \leqslant 1 \text { for all } y \in \mathbf{R} \text {. }
$$

And so $r$ has no pole on the axis $\operatorname{Re} z=0$. Therefore $q$ cannot have a root on this axis : indeed $q\left(i y_{0}\right)=0$ implies $q\left(-i y_{0}\right)=0$ and $y_{0} \neq 0$ for $q(0)=1$; since $i y_{0}$ and $-i y_{0}$ cannot be poles of $r, r$ may be written $r(z)=p_{1}(z) / q_{1}(z)$ with $d^{0} p_{1} \leqslant n-2$ and $d^{0} q_{1} \leqslant n-2$, which is incompatible with (2).

Now we set

$F_{n}=\left\{(a, b) ;(a, b) \in E_{n}\right.$ and the roots of $q$ belong to the closed half plane $\operatorname{Re} z \leqslant 0\}$ 
Since $q$ has no root on the imaginary axis, we have $F_{n}=\left\{(a, b) ;(a, b) \in E_{n}\right.$ and the roots of $q$ belong to the open half plane $\operatorname{Re} z<0\}$

We notice that $F_{n}$ is not empty; indeed the $(n-1 / n-1)-t$ Padé approximation to $e^{-z}$ is irreducible and it follows from the induction hypothesis that its denominator $A_{n-1}$ has no pole in the half plane $\operatorname{Re} z \geqslant 0$. We set

$$
p(z)=A_{n-1}(-z)(1+z) \text { and } q(z)=A_{n-1}(z)(1+z) ;
$$

then we have $(a, b) \in F_{n}$.

From (6) and (7) it follows that $F_{n}$ is an open and closed subset of $E_{n}$ and then we have $F_{n}=E_{n}$. Therefore if $(a, b) \in E_{n}, r$ is analytic in a neighbourhood of the half plane $\operatorname{Re} z \geqslant 0$; hence from the maximum principle and from (5) it follows that $r$ is $A$-acceptable.

Corollary 1: The Padé approximations to $e^{-z}$ of type $(n / n),(n-1 / n)$, $(n-2 / n)$ are A-acceptable.

Corollary 2: The poles of Padé approximations to $e^{-z}$ of type $(n / n)$, $(n-1 / n),(n-2 / n)$ belong to the open left half plane $\operatorname{Re} z<0$.

\section{REFERENCES}

1. B. L. EhLE, A-stable methods and Padé approximations to the exponential. SIAM. J. Math. Anal. 4, 1973, 671-680.

2. P. M. Hummel and C. L. SEebeCK, A generalization of Taylor's expansion. Amer. Math. Monthly, 56, 1949, p. 243-247.

3. S. P. NORSETT, C-Polynomials for rational approximation to the exponential function. Numer. Math. 25, 1975, p. 39-56.

4. H. PADE, Sur la représentation approchée d'une fonction par des fractions rationnelles. Thesis, Ann. de l'Ec. Nor. 9, 1892. 